\title{
DETERMINANTS OF BITCOIN PRICES
}

\section{DOI: 10.17261/Pressacademia.2019.1136 PAP-IFC- V.10-2019(4)-p.17-21}

\author{
E.Asena Deniz ${ }^{1}$, Dilek Teker ${ }^{2}$ \\ ${ }^{1}$ Isik University, Maslak , Istanbul, Turkey \\ elvanasena.deniz@isikun.edu.tr,ORCID: 0000-0003-1772-9714 \\ ${ }^{2}$ Isik University, Department of Business Administration, Sile, Istanbul, Turkey \\ dilek.teker@isikun.edu.tr, ORCID: 0000-0002-3983-4015
}

\section{To cite this document}

Deniz, A.E.,Teker,D., (2019). Determinants of Bitcoin prices. PressAcademia Procedia (PAP), V.10, p.17-21

Permemant link to this document: http://doi.org/10.17261/Pressacademia.2019.1136

Copyright: Published by PressAcademia and limited licenced re-use rights only.

\begin{abstract}
Purpose - The increase in the popularity of cryptocurrency market, various literature figure out the macroeconomic factors that effect the price movements of cryptocurrencies. This research aims to identify the interaction between gold, brent oil and bitcoin.

Methodology - The database includes the Daily prices of Bitcoin, gold and brent oil prices between the period of 28.04.2013-23.07.2019 which consist of 484 daily data. Natural logaritm for each indicator is used. First, the stationarity of the series were analyzed with ADF (Augmented Dickey Fuller) unit root test. Lag lengths are determined. Interactions between the series were analyzed by the ImpulseResponse Function and Variance Decomposition methods.

Findings- The series are found out to be stationary at first difference. Impulse response graphs indicate that all variables respond in a reducing way to reducing shocks occurred in each indicator. Shocks have lost their effect on average in 5 days.

Conclusion- The results indicate that the effect of gold and brent oil prices on bitcoin daily prices do not have a strong effect. The results may be beneficial for investors to consider diversification for the portfolios.
\end{abstract}

Keywords: Bitcoin, unit root tests, impulse response, variance decomposition JEL Codes: G10, G11, G15

\section{INTRODUCTION}

Digital values that allow encrypted secure transactions and additional virtual money supply are called cryptocurrencies. Cryptocurrencies are alternative currencies, they are digital and they are also virtual currencies. Cryptocurrencies are decentralized, unlike those in central electronic currencies and banking systems. Control of this decentralized structure is carried out by Block-Chain transaction databases. There are currently 2818 cryptocurrencies. However, the very well knowns are Bitcoin (BTC), Litecoin (LTC), Ethereum (ETH), Ripple (XRP), Bitcoin Cash (BCH), Ethereum Classic (ETC).After the 2008 crisis, Satoshi Nakamato, known as the creator of bitcoin, published his technical paper on Bitcoin, a peer-to-peer electronic payment system. Bitcoin is the first and most popular of what has become known as crypto currencies, digital monetary and payment systems that exist online via decentralized, distributed networks that employ a shared ledger data technology known as block-chain coupled with secure encryption. While it is possible to follow transactions entering the Bitcoin network, it is impossible to find out who carried out the transaction.

Polasik et al. (2015) group bitcoin research on four main areas. The first one examines technological and security issues, the second one public and legal issues, the third one political, sociological and ethical implications of bitcoin and other cryptocurrencies. The last one, in which our contribution lies, focuses on economic and financial issues from both a theoretical and an empirical perspective. 3 The existing empirical literature (Bouoiyour and Selmi, 2015, Ciaian et al., 2016a, Ciaian et al., 2016b, Kristoufek, 2013 has identified four main categories of drivers affecting the price of bitcoin: (1) market forces of supply and demand for bitcoin, (2) investment attractiveness of bitcoin, (3) global macroeconomic and financial developments and (4) bitcoin-technology-related factors. We mainly examine factors in the second and third categories. The expanding literature on bitcoin reflects the increased interest on the topic. Huhtinen (2014) finds an increase in the supply (i.e. total number of bitcoins mined) to cause a decrease in the price of bitcoin suggesting an inflationary effect of the increasing supply. Kristoufek (2013) supports the latter but only in the long term; in the short run the relationship is not significant and no conclusion can be drawn regarding the sign or the direction of causality. Similarly, Li and Wang (2017) find a significant effect only in the long-run, while Gronwald (2015) argues that the fluctuations in bitcoin price should be ascribed only to factors affecting demand, as there is no uncertainty on the supply-side. Kristoufek (2015) finds that in the long run bitcoin appreciates, as the demand for use in trade increases. An increase in price boosts exchange transactions in the short run suggesting that bitcoin's long-run behavior can be explained by the quantity theory of money. In the short run, it is susceptible to bubbles and busts. Polasik et al. (2015) find evidence that demand driven by the users' transactional needs leads to price increases, but supply is not statistically significant in affecting bitcoin returns, as it is determined through a known mathematical algorithm and, therefore, is more predictable. The findings of Bartos (2015) and Ciaian et 
al. (Ciaian et al., 2016a, Ciaian et al., 2016b) suggest that supply and - more profoundly - demand have a significant impact on the bitcoin price. The very weak relation between Bitcoin and other financial assets might be because Bitcoin does not share many common price determinants with those financial assets (Bouoiyour, Selmi, Tiwari, and Olayeni, 2016; Kristoufek, 2015). In fact, Bitcoin price depends less on economic and financial variables (Kristoufek, 2015) and more on a unique set of characteristics, such as attractiveness (Kristoufek, 2015), energy prices (Li \& Wang, 2017), user anonymity (Ober, Katzenbeisser, \& Hamacher, 2013), computer programming enthusiasts, and illegal activity (Yelowitz \& Wilson, 2015). So far, a limited number of studies have considered Bitcoin, gold, and other commodities (crude oil). Importantly, this scant empirical literature covers gold and Bitcoin markets (Bouoiyour \& Selmi, 2015; Bouri, Molnár, et al., 2017; Corbet et al., 2018; Dyhrberg, 2016a; Kristoufek, 2015), without making a comparable analysis between their roles against stock market indices. This research aims to identify the interaction between gold, brent oil on bitcoin daily price movements. The database includes the daily prices of Bitcoin, gold and brent oil prices between the period of 28.04.2013-23.07.2019 which consist of 484 daily data.

\section{DATA AND METHODOLOGY}

The study was carries out with daily data of Bitcoin, gold and brent oil prices between the periods April 28, 2013 to July 23,2019 that consist 484 data. Natural logarithms of all series were used in the analysis. The data is obtained from www.investing.com. In this study, the stationary of the series were analyzed with ADF (Augmented Dickey Fuller) unit root tests. Interactions between the series were analyzed by the Impulse-Response Function and Variance Decomposition methods based on the VAR (Vector Aotoregressive) method. Unit root testing is an important methodology for testing whether shocks to a particular time series have a permanent effect or a transitory effect. The presence of a unit root suggests that after a shock the series has no tendency to revert to its equilibrium value or stable path. On the other hand, if it is possible to reject the null hypothesis of unit root then this indicates that the shocks to a series only have a transitory effect. The hypotheses for unit root tests areas:

$H_{0}$ : Series are not stationary.

$H_{1}$ : Series are stationary.

Stationarity of series can be determined by unit root tests. In the study, the stationary level of the series was tested with ADF and PP methods. Among these tests, ADF is preferred for being the most widely used test while PP is preferred because it is accepted stronger than ADF (Arltova ve Fedorová, 2016) in the analysis which includes trend. The outputs indicate that seres become stationary after taking their first differences are called as I(1) (Dikmen, 2012). Table 1 indicates the outputs of ADF unit root tests.

Table 1: Unit Root Test Results

\begin{tabular}{|c|c|c|c|c|c|c|c|c|}
\hline \multicolumn{9}{|c|}{ ADF UNIT ROOT TEST } \\
\hline \multicolumn{3}{|c|}{ LNBITCOIN } & \multicolumn{3}{|c|}{ LNGOLD } & \multicolumn{3}{|c|}{ LNBRT } \\
\hline TEST STATISTIC & CRITICAL VALUES & PROBABILITY VALUE & TEST STATISTIC & CRITICAL VALUES & PROBABILITY VALU & TEST STATISTIC & CRITICAL VALUES & PROBABILITY VALUE \\
\hline \multirow{3}{*}{-20.66927} & -3.443691 & 0.00000 & \multirow{3}{*}{-16.74502} & -3.443748 & 0.00000 & \multirow{3}{*}{-22.16681} & -3.443691 & 0.00000 \\
\hline & -2.867317 & 0.00000 & & -2.867342 & 0.00000 & & -2.867317 & 0.00000 \\
\hline & -2.569909 & 0.00000 & & -2.56992 & 0.00000 & & -2.569909 & 0.00000 \\
\hline
\end{tabular}

The VAR analysis developed by Sims (1980) was preferred in this study because it allows to analyze the interactions between variables simultaneously (Trenca and Mutu, 2011). The relationships between factors that move simultaneously especially like monetary theory and financial instruments can be analyzed effectively by the VAR method (Triacca, 2017). There are so many criteria used in the literature to determine the lag length of an AR process. Criteria that have been evaluated in this study are as follows: Akaike's information criterion (AIC), Schwarz information criterion (SIC), Hannan-Quinn criterion(HQC), Final prediction error (FPE). The outputs for the lag length criteria figures out the length as 2 periods. Impulse response or dynamic multiplier analysis is a common tool for investigating the interrelationships among the variables in dynamic models. In such systems it is assumed that although the individual variables are nonstationary, there are linear combinations of them which are stationary. These linear combinations are often interpreted as long-run equilibrium relations. In other words, it is assumed that the deviations from the equilibrium relations are stationary. Consequently, assuming that the variables are in an equilibrium at some time $t$, say $t=0$, any shock to one of the variables will result in time paths of the system that will eventually settle down in a new equilibrium provided no further shocks occur. This analysis examines the responses of variables located in the VAR model to their own or other variables' shocks. A standard-error shock occurred in one of the variables is examined by the response of the series itself and other variables (Rossi, 2011). In the study, generalized shocks are given while creating effect-response functions. The results are presented below: 


\section{Figure 1: Impulse Response Test Results}

Response of DLBITCOIN to DLBITCOIN

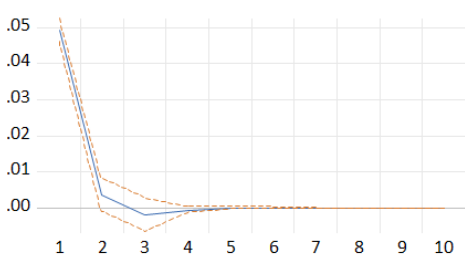

Response of DLBRENTPETROL to DLBITCOIN

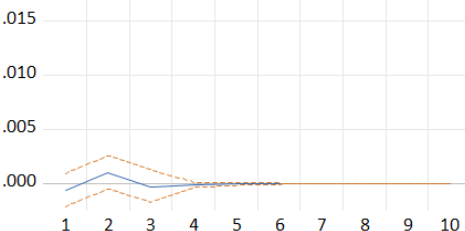

Response of DLGOLD to DLBITCOIN

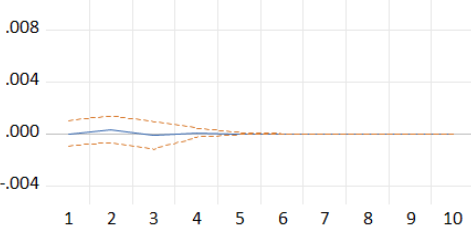

Response of DLBITCOIN to DLBITCOIN

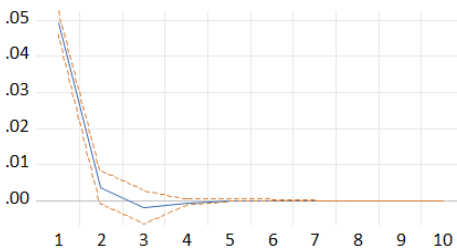

Response of DLBRENTPETROL to DLBITCOIN

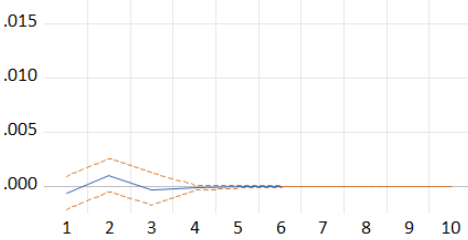

Response of DLGOLD to DLBITCOIN

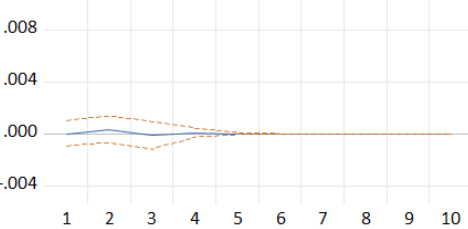

Response of DLBITCOIN to DLBRENTPETROL

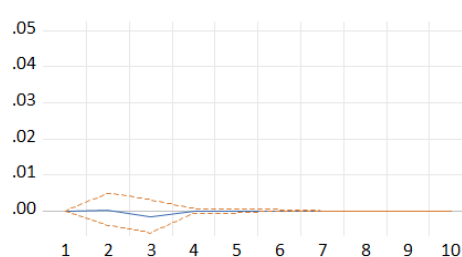

Response of DLBRENTPETROL to DLBRENTPETROL

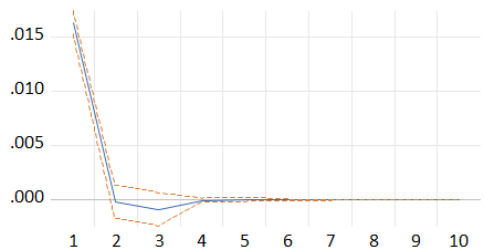

Response of DLGOLD to DIBRENTPETROL

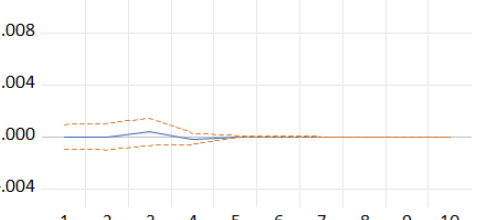

Response of DLBITCOIN to DLBRENTPETROL

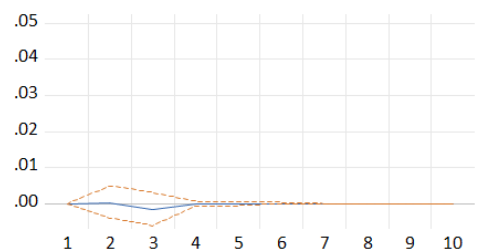

Response of DLBRENTPETROL to DLBRENTPETROL

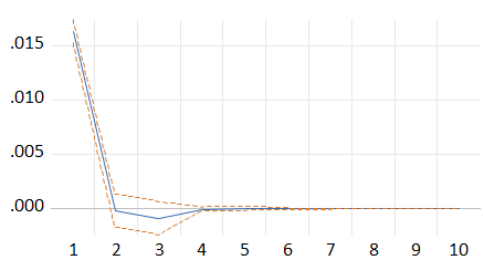

Response of DLGOLD to DLBRENTPETROL

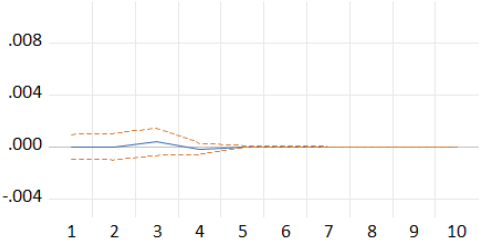

Response of DLBITCOIN to DLGOLD

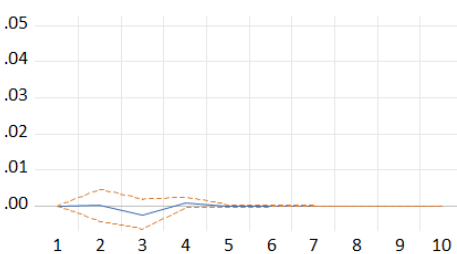

Response of DLBRENTPETROL to DLGOLD

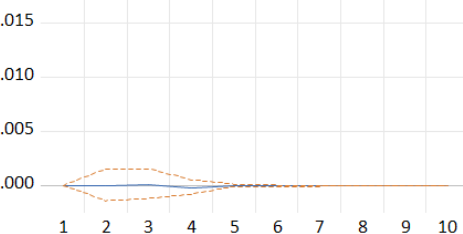

Response of DLGOLD to DLGOLD

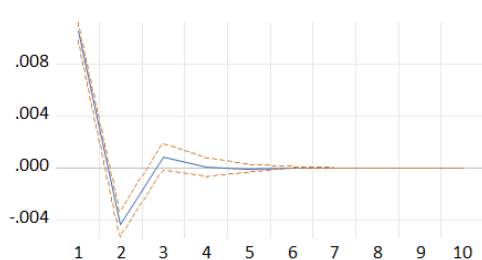

Response of DLBITCOIN to DIGOLD

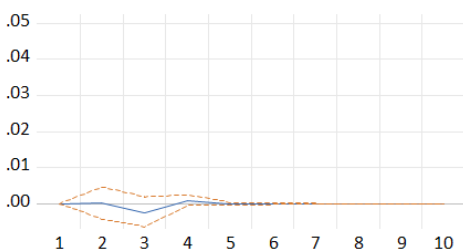

Response of DLBRENTPETROL to DLGOLD

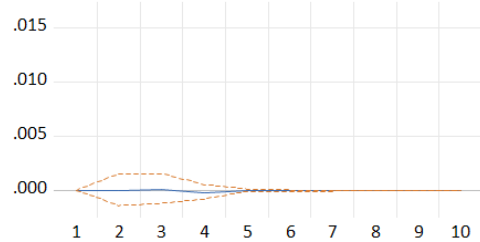

Response of DLGOLD to DLGOLD

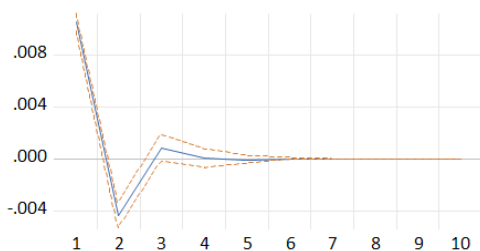

As analysed from figure 1; Impulse response graphs indicate that all variables respond in a reducing way to reducing shocks occurred in each indicator. Shocks have lost their effect on average in 5 days.

Finally, variance decomposition method is used to determine how much of the change in each variable arises from changes in other variables and arises from itself. The outputs for Bitcoin is illustrated in Table 2. 
Table 2: Variance Decomposition Test Results

\begin{tabular}{|r|c|c|c|}
\hline \multicolumn{4}{|c|}{ Variance Decomposition of DLBITCOIN } \\
\hline 1 & DLBITCOIN & DLBRENTPETROL & DLGOLD \\
\hline 2 & 900.0000 & 0.000000 & 0.000000 \\
\hline 3 & 99.99210 & 0.005900 & 0.001999 \\
\hline 4 & 99.66500 & 0.093200 & 0.241797 \\
\hline 5 & 99.63837 & 0.093689 & 0.267792 \\
\hline 6 & 99.63823 & 0.093783 & 0.267845 \\
\hline 7 & 99.63822 & 0.093876 & 0.267895 \\
\hline 8 & 99.63821 & 0.093878 & 0.267903 \\
\hline 9 & 99.63821 & 0.093877 & 0.267902 \\
\hline 10 & 99.63820 & 0.093877 & 0.267902 \\
\hline
\end{tabular}

After7th period, in the distribution, equilibrium was established. In this case, $99.63 \%$ of the changes in BITCOIN were caused by itself, less than $1 \%$ from Brent Oil and gold.

\section{CONCLUSION}

In this study, the interaction between the closing prices of the Bitcoin, gold and Brent Oil is analysed. In this study, the stationary of the series were analyzed with ADF (Augmented Dickey Fuller) unit root tests. The series were examined by ADF unit root tests and it was observed that all series were (1). Interactions between the series were analyzed by the Impulse-Response Function. Impulse response graphs indicate that all variables respond in a reducing way to reducing shocks occurred in each indicator. Shocks have lost their effect on average in 5 days. Next Variance Decomposition method is based on the VAR (Vector Aotoregressive) method. Finally, variance decomposition method is used to determine how much of the change in each variable arises from changes in other variables and arises from itself. The outputs highlight that after 7th period, in the distribution, equilibrium was established. In this case, $99.63 \%$ of the changes in BITCOIN were caused by itself, less than $1 \%$ from Brent Oil and gold.Based on the findings obtained from this study, it can be understood that there is no significant interactions between Bitcoin, gold and brent oilium. The result may be beneficial for investors to consider diversification for their portfolios. The results may change when implemented to other cryptocurrencies.

\section{REFERENCES}

Arltová,M., FEDOROVÁ, D.(2016). Selection of unit root test on the basis of length of the time series and value of AR (1) parameter. Statistika,96(3)

Bartos, J. (2015). Does bitcoin follow the hypothesis of efficient market? Interna- tional Journal of Economic Sciences, IV(2):10-23.

Bouoiyour, J. and Selmi, R. (2015). What does bitcoin look like? Annals of Economics and Finance, 16(2):449-492.

Bouoiyour, J., Selmi, R., Tiwari, A. K., \& Olayeni, O. R. (2016). What drives Bitcoin price? Economics Bulletin, 36(2), 843-850.

Bouri, E., Molnár, P., Azzi, G., Roubaud, D., \& Hagfors, L. I. (2017). On the hedge and safe haven properties of Bitcoin: Is it really more than a diversifier? Finance Research Letters, 20, 192-198.

Ciaian, P., Rajcaniova, M., and Kancs, D. (2016a). The digital agenda of virtual currencies: Can bitcoin become a global currency? Information Systems and e-Business Management, 14(4):883-919.

Ciaian, P., Rajcaniova, M., and Kancs, D. (2016b). The economics of bitcoin price formation. Applied Economics, 48(19):3-1815.

Corbet, S., Meegan, A., Larkin, C., Lucey, B., \& Yarovaya, L. (2018). Exploring the dy- namic relationships between cryptocurrencies and other financial assets. Economics Letters, 165, 28-34.

Dikmen, Nedim (2012). Ekonomtri Temel Kavramlar ve Uygulamalar. 2. Baskı, Bursa: Dora Yayınları.

Dyhrberg, A. H. (2016a). Bitcoin, gold and the dollar-A GARCH volatility analysis. Finance Research Letters, 16, 85-92. 
FEDOROVÁ, D. Vybrané testy jednotkových kořenů v časových řadách. Diploma thesis, Prague: VŠE, 2016.

Gronwald, M. (2015). The economics of bitcoins - news, supply vs. demand and jumps. Discussion Paper in Economics, 17(15). University of Aberdeen Business School.

Huhtinen, T.-P. (2014). Bitcoin as a monetary system: Examining attention and at- tendance. Master's thesis, Aalto University School of Business.

Li, X. and Wang, C. A. (2017). The technology and economic determinants of cryp- tocurrency exchange rates: The case of bitcoin. Decision Support Systems, 95:49-60.

Kristoufek, L. (2013). Bitcoin meets google trends and wikipedia: Quantifying the relationship between phenomena of the internet era. Scientific Reports, 3.

Kristoufek, L. (2015). What are the main drivers of the bitcoin price? Evidence from wavelet coherence analysis. Plos One, 10(4).

Ober, M., Katzenbeisser, S., \& Hamacher, K. (2013). Structure and anonymity of the bitcoin transaction graph. Future Internet, 5(2), 237250.

Polasik, M., Piotrowska, A. I., Wisniewski, T. P., Kotkowski, R., and Lightfoot, G. (2015). Price fluctuations and the use of bitcoin: An empirical inquiry. Inter- national Journal of Electronic Commerce, 20(1):9-49.

Rossi, E. (2011). Impulse response functions. http://economia.unipv.it/pagp/pagine_personali /erossi/dottorato_svar.pdf, [Access Date: 02.03.2019].

Sims, C. A. (1980). Macroeconomics and reality. Econometrica. 48, 1-48.

Trenca, I., Mutu, S. (2011). Advantages and limitations of VAR models used in managing market risk in banks. Finance - Challenges of the Future, 13, 32-43.

Triacca, U. (2017). Vector autoregressive models. http://www.phdeconomics.sssup.it/ documents/Lesson17.pdf, [Access Date: 02.03.2019]

Yelowitz, A., \& Wilson, M. (2015). Characteristics of Bitcoin users: An analysis of Google search data. Applied Economics Letters, 22(13), 1030-1036. 